\title{
Left-Right Locomotor Circuitry Depends on RhoA-Driven Organization of the Neuroepithelium in the Developing Spinal Cord
}

\author{
Kei-ichi Katayama, ${ }^{1}$ Jennifer R. Leslie, ${ }^{1}$ Richard A. Lang, ${ }^{2}$ Yi Zheng, ${ }^{3}$ and Yutaka Yoshida ${ }^{1}$ \\ Divisions of ${ }^{1}$ Developmental Biology, ${ }^{2}$ Pediatric Ophthalmology, and ${ }^{3}$ Experimental Hematology and Cancer Biology, Cincinnati Children's Hospital \\ Medical Center, Cincinnati, Ohio 45229
}

RhoA is a key regulator of cytoskeletal dynamics with a variety of effects on cellular processes. Loss of RhoA in neural progenitor cells disrupts adherens junctions and causes disorganization of the neuroepithelium in the developing nervous system. However, it remains essentially unknown how the loss of RhoA physiologically affects neural circuit formation. Here we show that proper neuroepithelial organization maintained by RhoA GTPase in both the ventral and dorsal spinal cord is critical for left-right locomotor behavior. We examined the roles of RhoA in the ventral and dorsal spinal cord by deleting the gene in neural progenitors using Olig2-Cre and Wnt1-Cre mice, respectively. RhoA-deleted neural progenitors in both mutants exhibit defects in the formation of apical adherens junctions and disorganization of the neuroepithelium. Consequently, the ventricular zone and lumen of the dysplastic region are lost, causing the left and right sides of the gray matter to be directly connected. Furthermore, the dysplastic region lacks ephrinB3 expression at the midline that is required for preventing EphA4-expressing corticospinal neurons and spinal interneurons from crossing the midline. As a result, aberrant neuronal projections are observed in that region. Finally, both RhoA mutants develop a rabbit-like hopping gait. These results demonstrate that RhoA functions to maintain neuroepithelial structures in the developing spinal cord and that proper organization of the neuroepithelium is required for appropriate left-right motor behavior.

\section{Introduction}

Mammalian motor behavior is controlled by different types of neural circuitry, including corticospinal circuitry and the central pattern generator (CPG). Corticospinal tracts (CSTs) play an important role in the control of voluntary movements by connecting the motor cortex with spinal motor neurons either directly or through interneurons in the spinal cord (Gianino et al., 1999; Canty and Murphy, 2008; Lemon, 2008), whereas CPGs are local networks of interneurons within the spinal cord that generate repetitive sequential movements of limbs for activities such as walking (Kiehn and Kullander, 2004; Goulding, 2009). Numer-

Received Dec. 27, 2011; revised June 6, 2012; accepted June 6, 2012.

Author contributions: K.K. and Y.Y. designed research; K.K. and J.R.L. performed research; R.A.L. and Y.Z. contributed unpublished reagents/analytic tools; K.K. analyzed data; K.K. and Y.Y. wrote the paper.

Y.Y. is supported by National Institute of Neurological Disorders and Stroke Grant NSO65048, and K.K. was supported by Japan Society for the Promotion of Science Postdoctoral Fellowships for Research Abroad. We are grateful to Drs. Thomas M. Jessell (Columbia University, New York, NY) and Bennett G. Novitch (University of California, Los Angeles, Los Angeles, (A) for providing us with Hb9-EGFP and Olig2-Cre mice as well as antibodies, and Drs. Kamal Sharma (University of Chicago, Chicago, IL), Eric E. Turner (Seattle Children's Institute, Seattle, WA), Thomas Müller (Max Delbrück Center for Molecular Medicine, Berlin, Germany), and Qiufu Ma (Harvard Medical School, Boston, MA) for providing antibodies for our work. We thank Dr. Masaki Ueno (Osaka University, Osaka, Japan) for his advice on CST labeling and Drs. Masato Nakafuku, Kenneth Campbell, Chia-Yi Kuan (Cincinnati Children's Hospital Medical Center, Cincinnati, OH), and Laskaro Zagoraiou (University of Crete, Crete, Greece) for their helpful discussion and comments on this manuscript.

The authors declare no competing financial interests.

Correspondence should be addressed to Yutaka Yoshida, Division of Developmental Biology, Cincinnati Children's Hospital Medical Center, 3333 Burnet Avenue, Cincinnati, OH 45229. E-mail: yutaka.yoshida@cchmc.org.

DOI:10.1523/JNEUROSCI.6474-11.2012

Copyright $\odot 2012$ the authors $\quad 0270-6474 / 12 / 3210396-12 \$ 15.00 / 0$ ous studies have revealed that ephrinB3/EphA4 forward signaling is essential for the formation of CSTs and the CPG (Dottori et al., 1998; Kullander et al., 2001, 2003; Yokoyama et al., 2001; Beg et al., 2007; Fawcett et al., 2007; Iwasato et al., 2007; Wegmeyer et al., 2007). In the developing spinal cord, ephrinB3 localizes at the midline and prevents corticospinal neurons and spinal interneurons, including those of the CPG, from crossing to the other side of the spinal cord by generating repulsive signals through EphA4 receptors expressed on those nerve fibers. Mutant mice lacking molecules for the ephrinB3/EphA4 signaling pathway exhibit aberrant projections of corticospinal neurons and interneurons across the midline and display abnormal left-right walking behavior (i.e., a rabbit-like hopping gait). Although much work has been done on ephrinB3/EphA4 signaling, the exact cellular and molecular mechanisms underlying the formation of CST circuitry and the CPG during development remain unclear.

RhoA, the founding member of the Rho family of small GTPases, plays a variety of roles in nervous system development, including neuronal migration, axon guidance, and synapse formation (Koh, 2006; Linseman and Loucks, 2008). RhoA deletion in the forebrain, midbrain, and spinal cord was shown recently to induce disruption of adherens junctions (AJs) in neural progenitors and cause disorganization of the neuroepithelium (Herzog et al., 2011; Katayama et al., 2011; Cappello et al., 2012).

We set out to examine the roles of RhoA in spinal neural circuits and study the physiological effects of RhoA deletion on neural circuit formation. Deletion of $R h o A$ in a subset of neural progenitor cells, including motor neuron progenitors in the spi- 


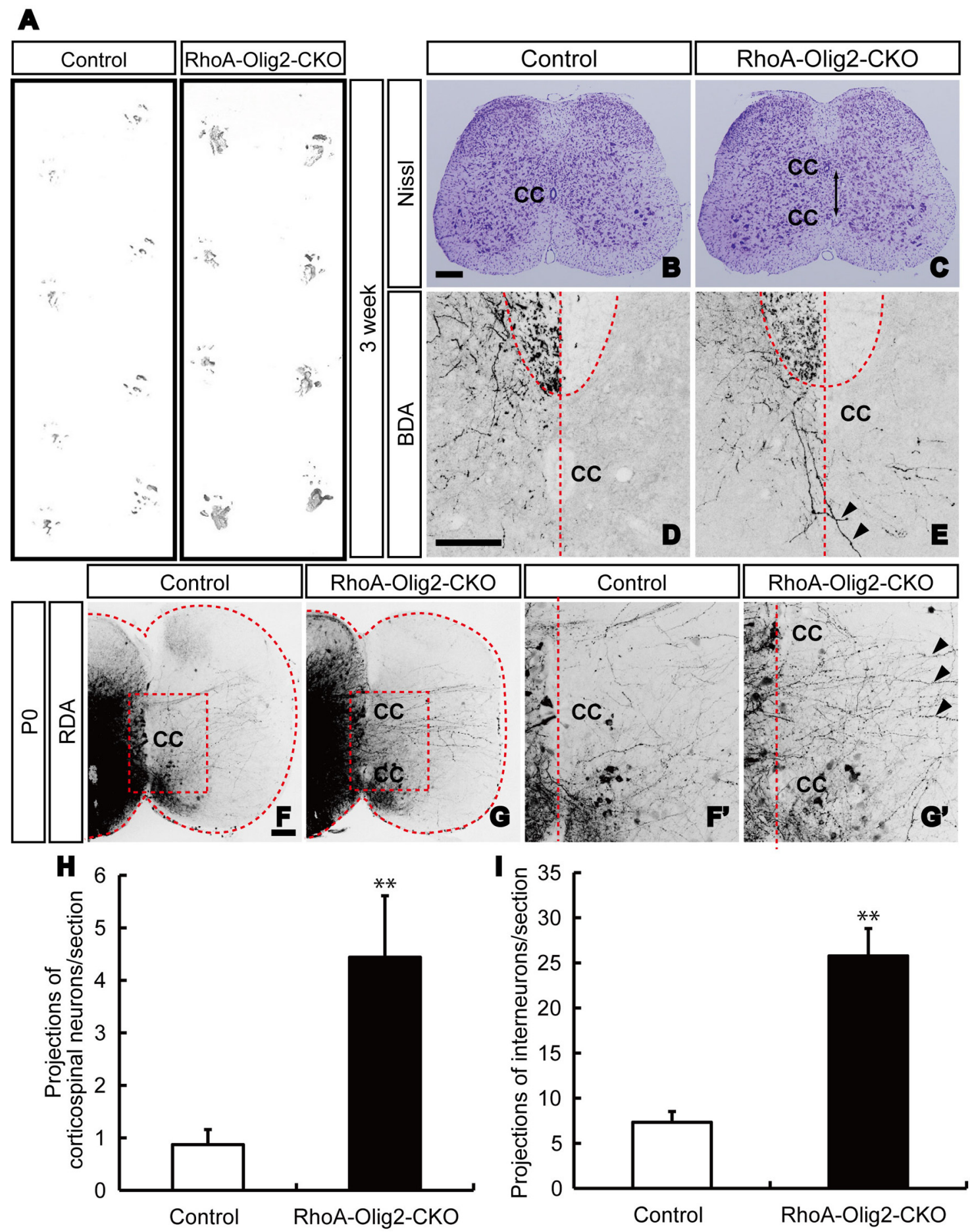

Figure 1. RhoA-0lig2-CKO mice exhibit a rabbit-like hopping gait and nerve fibers that aberrantly cross the spinal cord midline. $A$, Hindlimb footprint patterns of control and RhoA-Olig2-CKO mice. B, C, Nissl-stained sections of the spinal cords of 3-week-old mice. The central canal appeared to be split into two parts, and the gray matter was expanded in RhoA-0lig2-CKO mice. D, E, H, Anterograde tracing of the CST by BDA. Some CST axons aberrantly crossed the midline and projected to the other side of the spinal cord in RhoA-0lig2CKO mice (arrowheads). $\boldsymbol{F}, \mathbf{G}, \boldsymbol{F}^{\prime}, \boldsymbol{G}^{\prime}, \boldsymbol{I}$, Tracing of spinal interneurons by RDA. Numerous interneurons also projected to the contralateral side in RhoA-0lig2-CKO mice (arrowheads). $\boldsymbol{H}$, $I$, Bar graphs showing the number of neuronal projections across the midline of the spinal gray matter. The graphs represent the mean \pm SD of three to five mice. ${ }^{* *} p<0.01$, Student's $t$ test. CC, Central canal. Scale bars, $100 \mu \mathrm{m}$.

nal cord, using Olig2-Cre mice resulted in disrupted AJs and disorganized neuroepithelial structures in the ventral spinal cord. Corticospinal neurons and interneurons aberrantly crossed the midline through the dysplastic area that lacked ephrinB3 expression, resulting in abnormal neural circuits and altered walking behavior. Similar to Olig2-Cre mice, RhoA deletion using Wnt1-
Cre mice showed that proper neuroepithelial organization in the dorsal spinal cord was also required for left-right motor behavior. These results demonstrate that RhoA governs critical aspects of neuroepithelial organization in the developing spinal cord, shaping the neural circuitry controlling left-right walking behavior. 


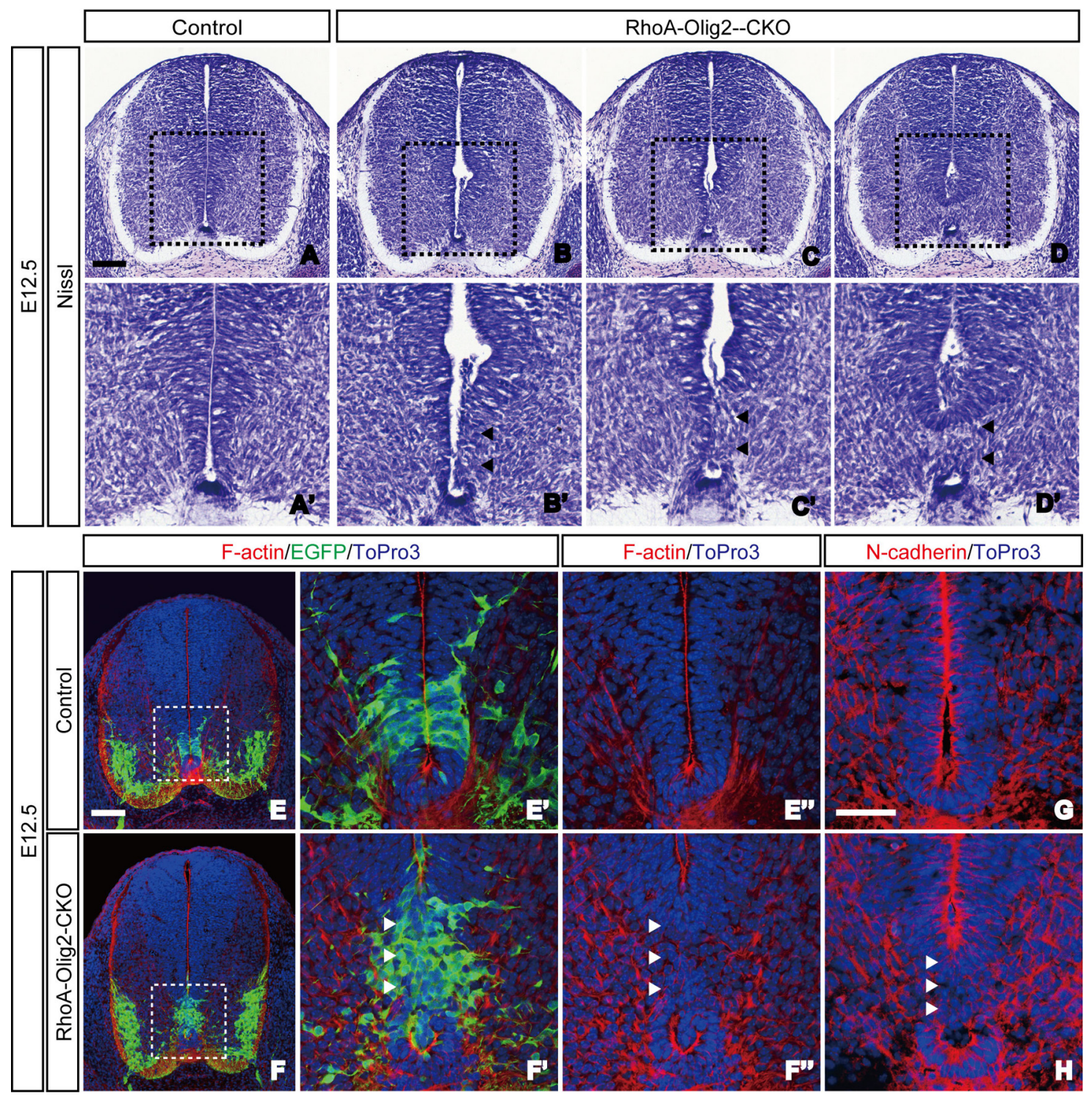

Figure 2. RhoA-0lig2-CK0 embryos exhibit disruption of AJs and disorganization of the neuroepithelium in the ventral spinal cord. $A-D, A^{\prime}-D^{\prime}$, Niss--stained sections of the spinal cord at E12.5. The apical organization of the ventral spinal cord became irregular, and the lumen of the central canal gradually collapsed in RhoA-0lig2-CK0 embryos (arrowheads). $\boldsymbol{E}_{\mathbf{1}} \boldsymbol{F}, \boldsymbol{E}^{\prime}, \boldsymbol{F}^{\prime}$, Dysplasia was observed in the same location as the EGFP ${ }^{+}$(Cre/loxP-recombined) region in RhoA-0lig2-CK0 embryos at E12.5. $\boldsymbol{E}^{\prime \prime}, \boldsymbol{F}^{\prime \prime}, \mathbf{G}, \boldsymbol{H}$, The apical localization of F-actin and N-cadherin was lost in the dysplastic region (arrowheads). Scale bars: $A, E, 100 \mu \mathrm{m} ; \boldsymbol{G}, 50 \mu \mathrm{m}$.

\section{Materials and Methods}

Animals. The following mouse strains were used in this study: RhoAfloxed (Chauhan et al., 2011; Katayama et al., 2011; Melendez et al., 2011), Olig2-Cre (Dessaud et al., 2007; Sürmeli et al., 2011), ChAT-Cre (Rossi et al., 2011), Wnt1-Cre (Danielian et al., 1998), lox-stop-loxEGFP (Nakamura et al., 2006), and Hb9-EGFP (Wichterle et al., 2002). Mice of both sexes were used, and $\mathrm{RhoA}^{\text {flox/+}} ; \mathrm{Cre}^{+}$mice were used as controls. In most of the figures, we present results from the lumbar spinal cord, but similar phenotypes were also found in cervical and thoracic levels of the spinal cord. Mouse handling and procedures were approved by the Institutional Animal Care and Use Committee at the Cincinnati Children's Hospital Research Foundation.

Tracing of corticospinal neurons and spinal interneurons. CST tracing experiments were performed as described previously (Omoto et al., 2011 ) with some modifications. Two-week-old animals were anesthetized with isoflurane, and the motor cortex was pressure injected with biotinylated dextran amine (BDA; Invitrogen), an anterograde tracer. Ten days after BDA injection, mice were killed and spinal cords were fixed in $4 \%$ paraformaldehyde (PFA). Vibratome sections (50 $\mu \mathrm{m}$ thick) were reacted with an Alexa Fluor 488-conjugated streptavidin (Invitrogen).

Analyses of the projections of interneurons within the spinal cord were performed as described previously (Kullander et al., 2003) with modifications. Spinal cords of embryonic day 15.5 (E15.5) mice, postnatal day 0 (P0) mice (Olig2-Cre mutants), and E18.5 embryos (Wnt1-Cre mutants) were dissected and unilaterally injected with tetramethylrhodamine-conjugated dextran amine (RDA; Invitrogen) into the second lumbar (L2) level. Preparations were incubated in oxygenated artificial CSF ( $137 \mathrm{~mm} \mathrm{NaCl}, 5 \mathrm{~mm} \mathrm{KCl}, 1$ mM $\mathrm{NaH}_{2} \mathrm{PO}_{4}, 24 \mathrm{~mm} \mathrm{NaHCO}, 0.2 \%$ D-glucose, $2 \mathrm{~mm} \mathrm{CaCl}_{2}$, and $1 \mathrm{~mm}$ $\mathrm{MgCl}_{2}$ ) at room temperature for $14-16 \mathrm{~h}$. Samples were then fixed in $4 \%$ PFA. Vibratome sections (60 $\mu \mathrm{m}$ thick) were reacted with a rabbit anti-tetramethylrhodamine antibody (Invitrogen), and positive signals were visualized with a Cy3-conjugated anti-rabbit IgG antibody (Jackson ImmunoResearch).

To examine the projections of spinal interneurons together with corticospinal neurons, we unilaterally injected small crystals of DiI (Invitrogen) into the PFA-fixed spinal cords in the L2-L4 region. The preparations were incubated at $37^{\circ} \mathrm{C}$ for 1 week to allow dye diffusion and then sectioned with a vibratome (200 $\mu \mathrm{m}$ thickness). 


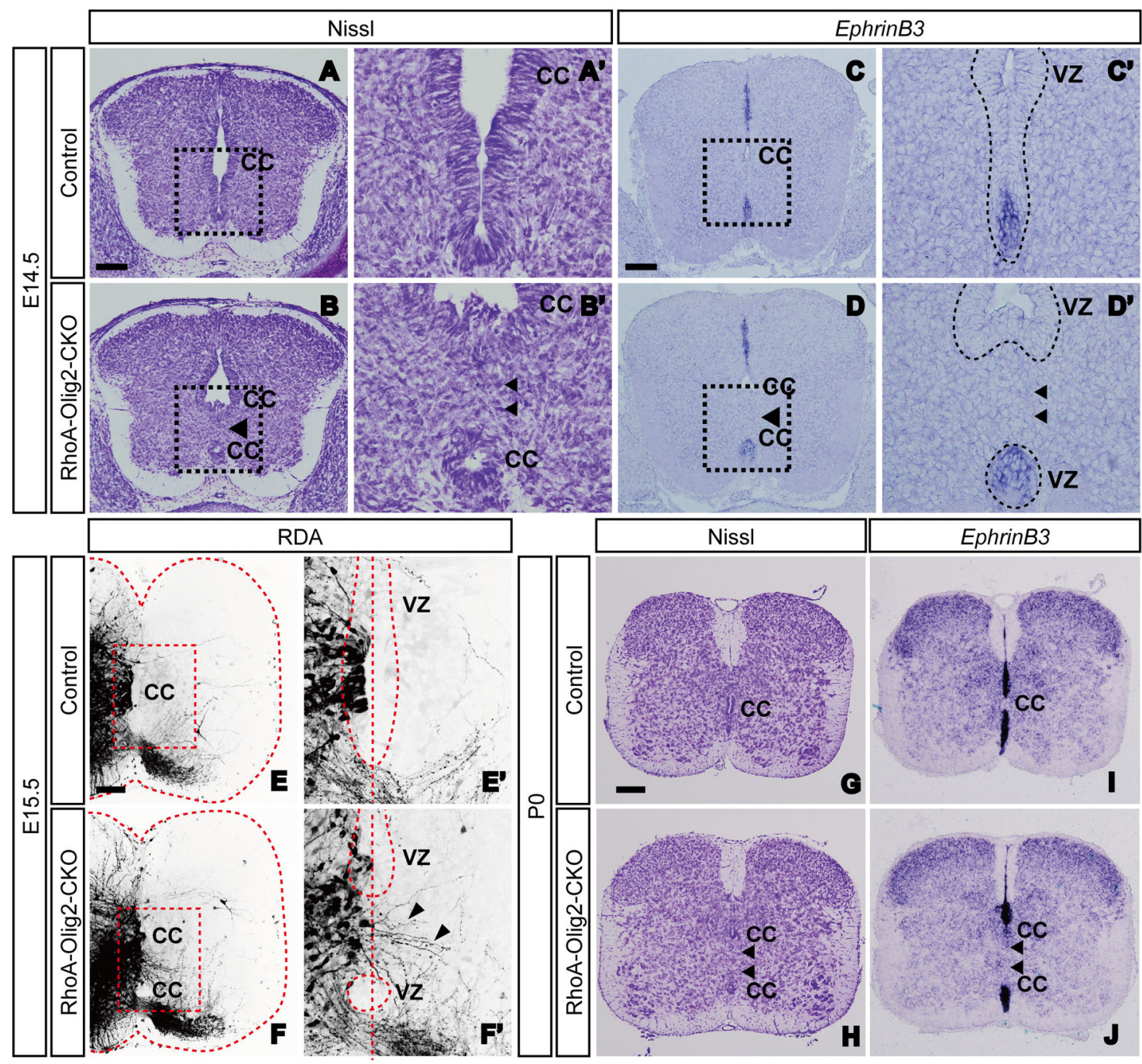

Figure 3. Disorganization of the neuroepithelium in the ventral spinal cord results in a direct connection between the left and right halves of the spinal gray matter and an ephrinB3-negative region in the dysplastic area in RhoA-0lig2-CK0 embryos. $\boldsymbol{A}, \boldsymbol{B}, \boldsymbol{A}^{\prime}, \boldsymbol{B}^{\prime}$, The ventricular zone and lumen of the central canal were partly absent in the ventral spinal cords of RhoA-0lig2-CK0 embryos at E14.5, resulting in a direct connection between the left and right halves of the spinal gray matter (arrowheads). $\boldsymbol{C}_{\mathbf{D}} \mathbf{D}, \mathbf{C}^{\prime}, \mathbf{D}^{\prime}$, EphrinB3 expression was absent in the dysplastic region (arrowheads). $\boldsymbol{E}, \boldsymbol{F}, \boldsymbol{E}^{\prime}, \boldsymbol{F}^{\prime}$, Spinal interneurons began to cross the midline and project to the other side of the spinal cord in RhoA-0lig2-CK0 embryos at E15.5 (arrowheads). $\mathbf{G}-\boldsymbol{J}$, The phenotype exhibiting a left-right connection in the spinal gray matter persisted in the ventral spinal cords of newborn RhoA-Olig2-CKO mice (PO; arrowheads). CC, Central canal; VZ, ventricular zone. Scale bars, $100 \mu \mathrm{m}$.

Histological analyses. Histological analyses were performed as described previously (Katayama et al., 2011; Leslie et al., 2011). Nissl stainings and in situ hybridizations were performed on PFA-fixed frozen sections. Immunohistochemistry was performed on frozen or vibratome sections and whole mounts using the following primary antibodies: mouse anti-N-cadherin (Invitrogen), mouse anti-RhoA (Santa Cruz Biotechnology), rabbit anti-GFP (Invitrogen), mouse anti-Isl1, mouse anti-neurofilament, mouse anti-Evxl (Developmental Studies Hybridoma Bank), guinea pig anti-Foxp1 (kindly provided by Dr. Bennett G. Novitch, University of California, Los Angeles, Los Angeles, CA), rabbit anti-Lhx3 (kindly provided by Dr. Kamal Sharma, University of Chicago, Chicago, IL), guinea pig anti-Isl1/2, rabbit anti-Nkx2.2 (kindly provided by Dr. Thomas M. Jessell, Columbia University, New York, NY), rabbit anti-Brn3a (Fedtsova and Turner, 1995; kindly provided by Dr. Eric E. Turner, Seattle Children's Institute, Seattle, WA), guinea pig anti-Lbx1 (kindly provided by Dr. Thomas Müller, Max-Delbrück-Center for Molecular Medicine, Berlin, Germany), and rabbit anti-Pax2 (kindly provided by Dr. Qiufu Ma, Harvard Medical School, Boston, MA). Positive signals were detected with secondary antibodies conjugated with Cy3 or Cy5 (Jackson ImmunoResearch) or Alexa Fluor 488 (Invitrogen). To detect apoptotic cells, we performed the TUNEL method using the ApopTag fluorescein in situ apoptosis detection kit (Millipore). We also used phalloidin-tetramethylrhodamine B isothiocyanate (Sigma) and ToPro3 (Invitrogen) to visualize F-actin and nuclei, respectively. Images were taken with an Axio Imager Z1 microscope and a LSM510 confocal microscope (Carl Zeiss). For data quantitation, antibody-bound cells were counted using AxioVision software (Carl Zeiss).

\section{Results}

RhoA-Olig2-CKO mice exhibit a rabbit-like hopping gait

To determine the roles of RhoA in developing motor neuron progenitors and motor neurons, we deleted RhoA by crossing Rho $A^{\text {flox/flox }}$ mice with Olig2-Cre mice, in which Cre recombination begins in motor neuron progenitors as early as E9.5 (Dessaud et al., 2007; Sürmeli et al., 2011). RhoA flox/flox; Olig2-Cre (hereafter referred to as RhoA-Olig2-CKO) mice were born in the expected Mendelian ratios with the mutant mice exhibiting a rabbit-like hopping gait (Fig. $1 A$ ). Nissl-stained sections of the spinal cords of RhoA-Olig2-CKO mice showed that the central canal seemed to be split into two parts (Fig. $1 C$ ): one located dorsally and the other in the most ventral part of the gray matter (Fig. 1C). In addition, the gray matter at the midline was ex- 

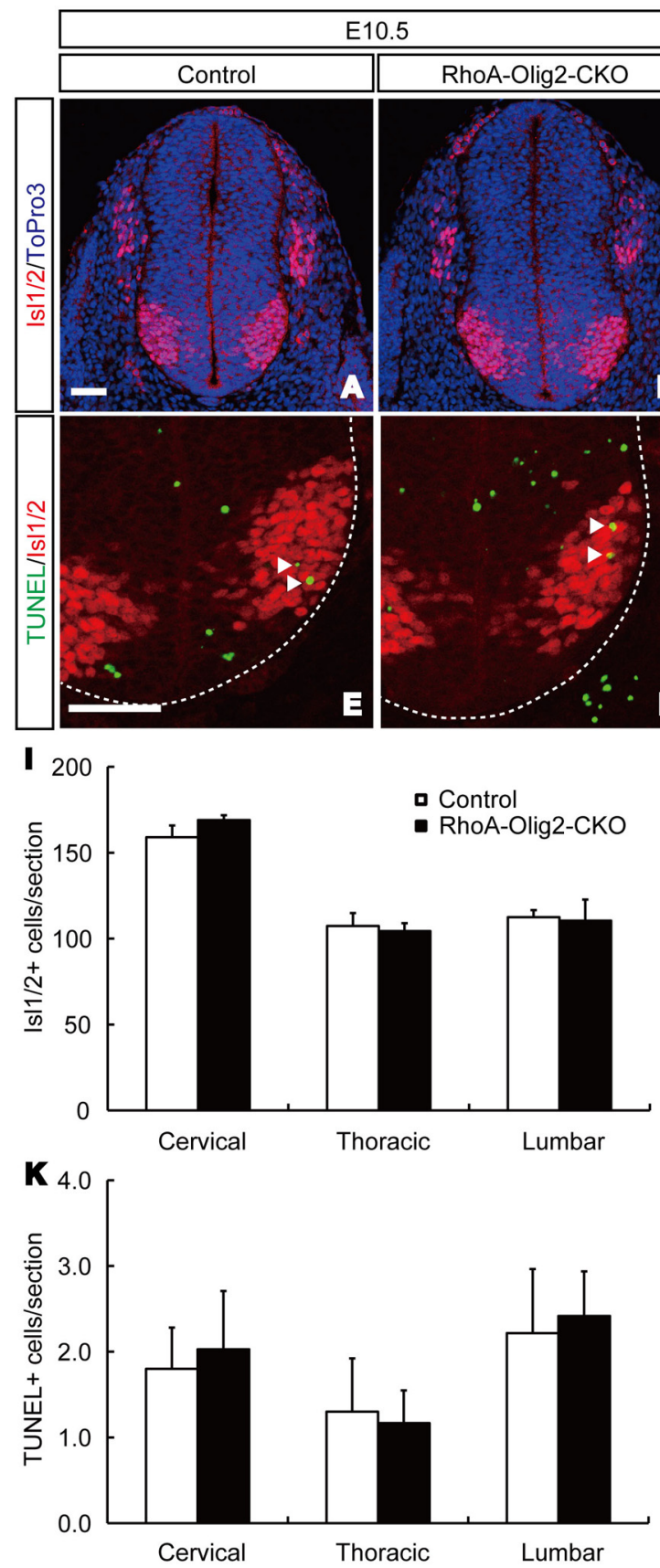
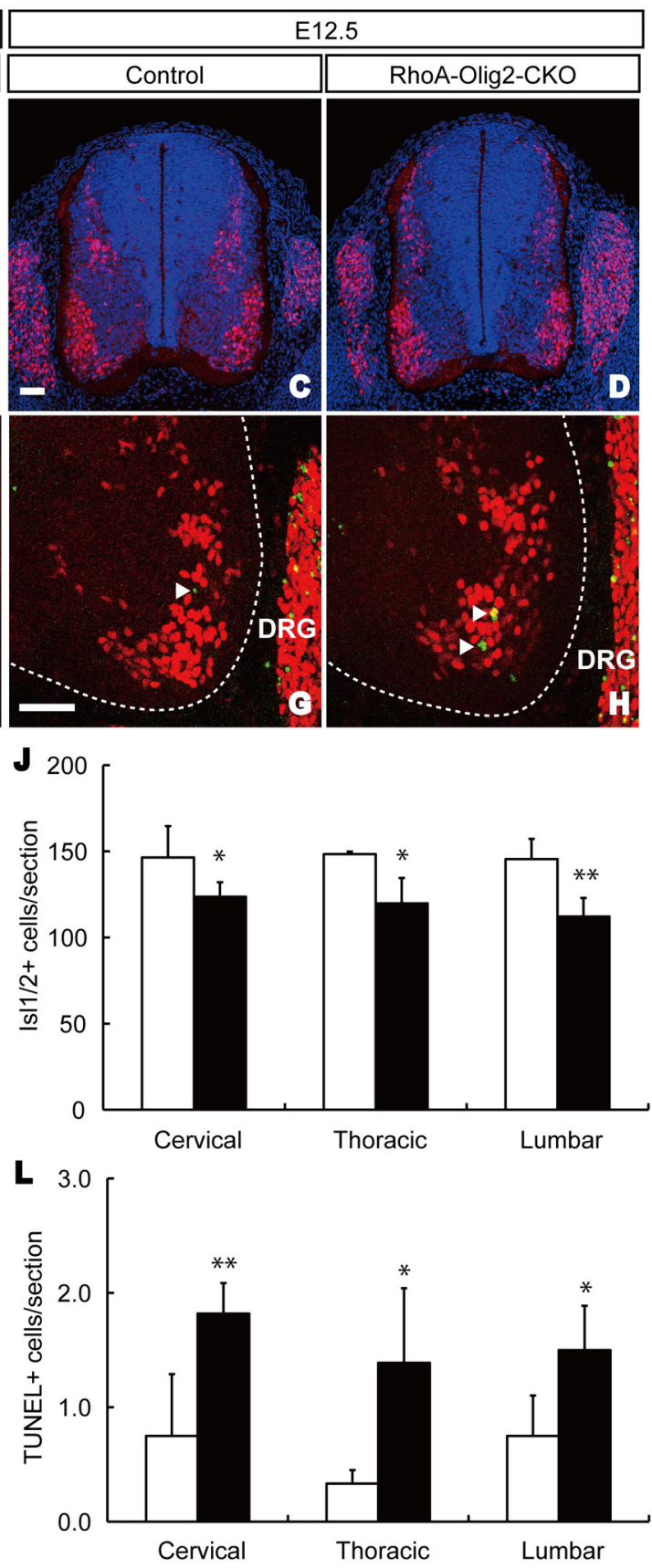

Figure 4. RhoA plays a role in the survival of motor neurons in the developing spinal cord. $A-D, I, J$, The number of Is $11 / 2^{+}$motor neurons in RhoA-0lig2-CKO embryos was not significantly different from that of control embryos at E10.5 but was significantly decreased atE12.5. $\boldsymbol{E}-\boldsymbol{H}, \boldsymbol{K}, \boldsymbol{L}$, The number of TUNEL ${ }^{+}$cells among the Is $11 / 2{ }^{+}$motor neurons in RhoA-0lig2-CK0 embry0s was also similar to that of control embryos at E10.5, but, at E12.5, TUNEL ${ }^{+}$cells showed a significant increase. The graphs represent the mean \pm SD of three to six embry0s. ${ }^{*} p<0.05,{ }^{* *} p<0.01$, Student's t test. DRG, Dorsal root ganglion. Scale bars, $50 \mu \mathrm{m}$.

panded compared with control mice (Fig. $1 B, C$ ). We then examined the axonal projections of the CSTs, which are important for controlling voluntary movements. After BDA injection into one side of the motor cortex, we found that, in control mice, CST axons projected from the dorsal funiculus to the gray matter of the same side of the spinal cord and rarely crossed the midline, whereas significant numbers of CST axons crossed the midline and projected to the other side through the expanded gray matter in RhoA-Olig2-CKO mice (Fig. $1 D, E, H$ ). We subsequently examined projections of interneurons within the spinal cord by injecting RDA into one side of the spinal cords of newborn mice. Although only several commissural projections to the contralat- eral side were observed in control spinal cords, numerous interneurons projected to the contralateral side through the expanded gray matter in RhoA-Olig2-CKO mice (Fig. $1 F, G, I$ ). These results demonstrate that RhoA is necessary for preventing aberrant midline crossing of both corticospinal neurons and interneurons in the spinal cord.

Disorganization of midline structure and absence of ephrinB3 expression in the dysplastic region in the ventral spinal cords of RhoA-Olig2-CKO embryos

To determine what causes the aberrant projections of corticospinal neurons and interneurons in RhoA-Olig2-CKO mice, we 
conducted detailed histological analyses. In RhoA-Olig2-CKO embryos, the localization of Olig2-expressing $\left(\mathrm{Olig}_{2}{ }^{+}\right.$) progenitors of spinal motor neurons in the ventral spinal cord was not altered at E10.5 (data not shown). At E12.5, Nissl-stained sections showed defects in the ventral midline structure and a collapsed lumen in the central canal (Fig. $2 A-D$ ). To detect the locations of Olig2-Cre-mediated Cre/loxP recombination, we crossed RhoA-Olig2-CKO mice with stop-floxed EGFP reporter mice (Nakamura et al., 2006) and found that the dysplastic region corresponded well with $\mathrm{EGFP}^{+}$areas (Fig. $2 \mathrm{E}, F$ ). To determine whether there were defects in AJ formation in RhoA-Olig2-CKO embryos, we examined the localization of F-actin and $\mathrm{N}$-cadherin and found that apical staining of F-actin and $\mathrm{N}$-cadherin in the dysplastic area had been lost (Fig. $2 E-H$ ). These results reveal that the loss of RhoA in Olig2 ${ }^{+}$progenitors induces disruption of apical AJs and disorganization of the neuroepithelium in the ventral spinal cord.

At E14.5, the ventricular zone and lumen were partly lost in the ventral spinal cords of RhoA-Olig2-CKO embryos, creating a direct connection between the left and right sides of the gray matter (Fig. $3 A, B$ ). In the developing spinal cord, expression of ephrinB3, which is required to prevent EphA4 ${ }^{+}$nerve fibers of corticospinal neurons and interneurons from crossing the midline, begins in the floor and roof plates and gradually expands medially to form the midline from E13.5 to E15.5 (Imondi et al., 2000). EphrinB3 expression was absent in the dysplastic region at E14.5 (Fig. 3C,D), and, by E15.5, some interneurons had extended neurites through this region in RhoA-Olig2-CKO embryos (Fig. 3E,F). The ephrinB3-negative area persisted to the newborn stage in RhoA-Olig2-CKO mice (Fig. 3G-J). Because CST axons begin to project into the spinal cord after birth (Gianino et al., 1999), we postulate that they would also likely cross the midline through this ephrinB3-negative region.

We then examined the development of spinal interneurons in RhoA-Olig2-CKO embryos. Subpopulations of spinal interneurons can be identified by the expression of specific homeodomain transcription factors (Jessell, 2000; Lee and Pfaff, 2001; Caspary and Anderson, 2003), and we performed immunohistochemistry for Brn3a (dI1-dI3, dI5), Lbx1 (dI4-dI6), Pax2 (dI4, dI6, V0d, V1), Evx1 (V0v), and Nkx2.2 (V3) in E13.5 embryos. However, the localization and number of interneurons positive for these markers in RhoA-Olig2-CKO embryos were similar to those in control embryos (data not shown), indicating that cell fate determination and migration of these spinal interneurons are not affected in RhoA-Olig2-CKO mice.

Together, our findings suggest that aberrant projections of corticospinal neurons and interneurons are caused by disorganization of the ventral midline structure with absence of ephrinB3 expression in the dysplastic area.

\section{Impaired motor neuron survival in RhoA-Olig2-CKO embryos}

Because Olig2 ${ }^{+}$progenitors differentiate into motor neurons, we examined the development of motor neurons in RhoA-Olig2$\mathrm{CKO}$ mice to determine whether the dysfunction of motor neurons also contributes to the rabbit-like hopping gait. RhoA has been shown to mediate motor neuron survival by expressing a dominant-negative form of RhoA in the developing motor neurons using a dopamine $\beta$-hydroxylase-Cre driver (Kobayashi et al., 2004). We first examined the number of Isl $1 / 2^{+}$motor neurons in RhoA-Olig2-CKO embryos (Tsuchida et al., 1994). Although there were no obvious differences in the number of motor neurons between control and RhoA-Olig2-CKO embryos at E10.5, RhoA-Olig2-CKO embryos showed a slight but signifi-

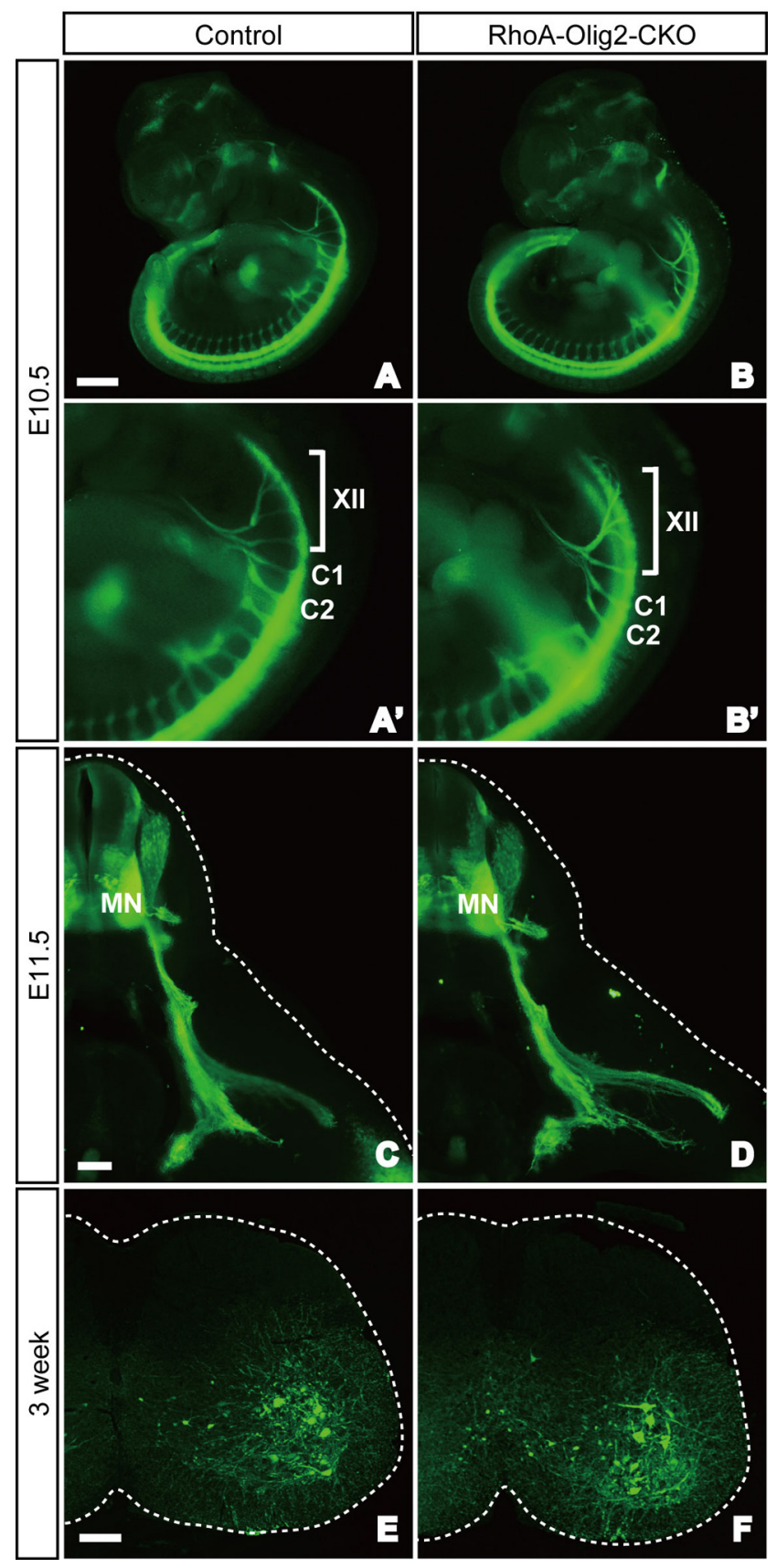

Figure 5. Loss of RhoA does not affect the axonal and dendrite projections of motor neurons To visualize the motor neuron axon and dendrite projections, RhoA-0lig2-CKO mice were crossed with Hb9-EGFP mice. $\boldsymbol{A}, \boldsymbol{B}, \boldsymbol{A}^{\prime}, \boldsymbol{B}^{\prime}$, Whole-mount preparations of embryos at E10.5 showed no obvious defects in the projection of motor nerves, including the hypoglossal (XII) and cervical 1 and 2 (C1, C2) nerves in RhoA-0lig2-CK0 embryos. C, D, Transverse vibratome sections of the hindlimb region at E11.5 showed no obvious defects in the projections of motor nerves to the hindlimb in RhoA-0lig2-CKO embryos. $\boldsymbol{E}, \boldsymbol{F}$, Transverse sections of the lumbar spinal cord at 3 weeks of age. Dendrites of motor neurons did not appear to project to the other side of the spinal cord in RhoA-0lig2-CKO mice. MN, Motor neuron. Scale bars: $\boldsymbol{A}, 500 \mu \mathrm{m} ; \boldsymbol{C}$, E, $100 \mu \mathrm{m}$.

cant decrease in motor neurons in the cervical, thoracic, and lumbar levels of the spinal cord at E12.5 compared with control embryos (Fig. $4 A-D, I, J$ ). Concurrently with the decrease in motor neuron numbers, the number of $\mathrm{TUNEL}^{+}$apoptotic cells among the motor neurons was increased in RhoA-Olig2-CKO embryos at E12.5 compared with control embryos (Fig. $4 E-$ 


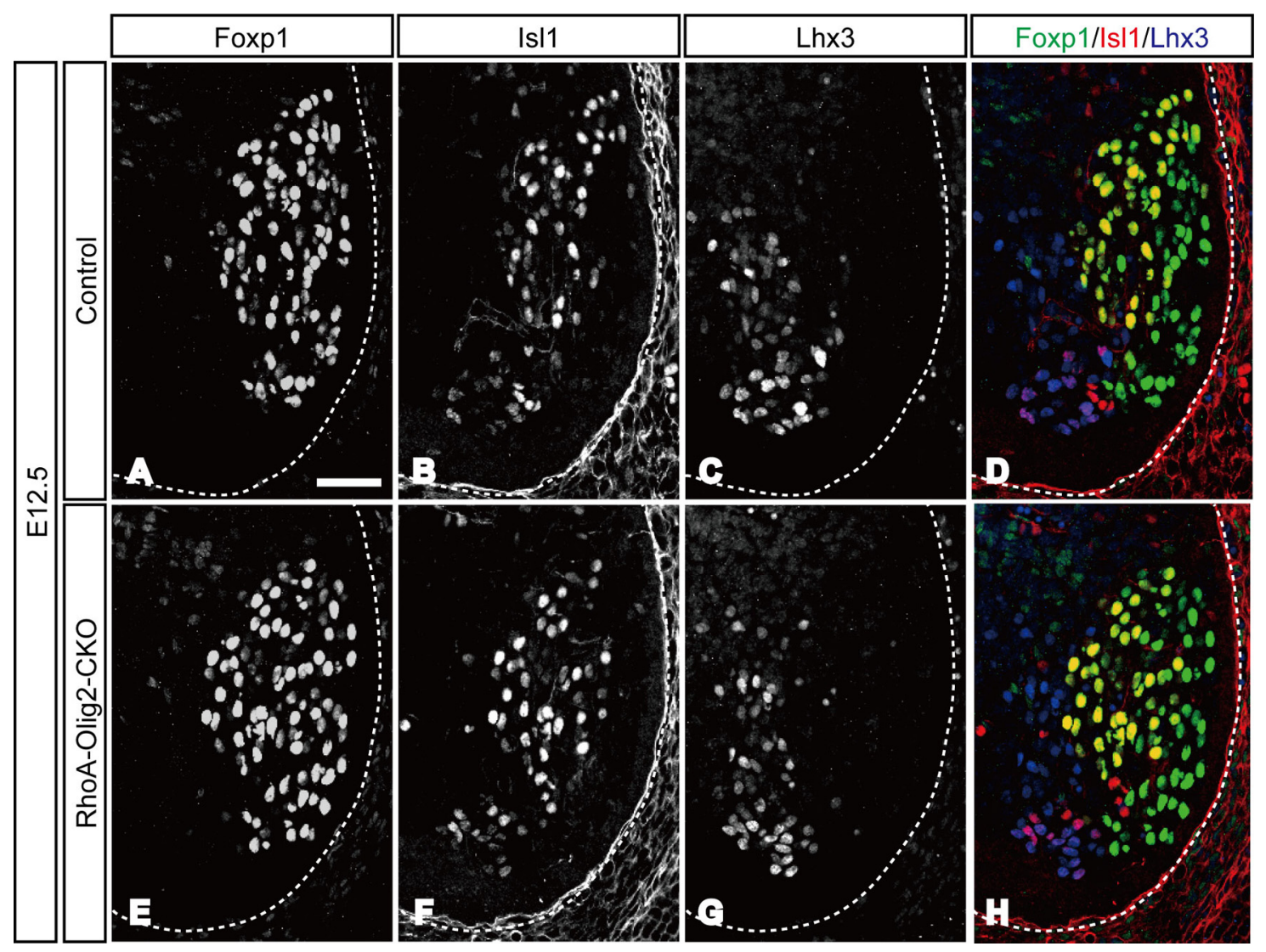

Figure 6. Loss of RhoA does not affect the distribution of motor neurons. Immunostaining for Foxp1 $(\boldsymbol{A}, \boldsymbol{E}), \mathrm{s} 11(\boldsymbol{B}, \boldsymbol{F})$, Lhx3 $(\boldsymbol{C}, \boldsymbol{G})$, and their merged images $(\boldsymbol{D}, \boldsymbol{H})$ of the lumbar spinal cord at E12.5. There were no obvious differences in the localization of motor neurons positive for each marker between control and RhoA-Olig2-CKO embryos. Scale bar, $50 \mu \mathrm{m}$.

$H, K, L)$. These results demonstrate that RhoA plays a role in the survival of developing motor neurons.

The conditional expression of a dominant-negative form of RhoA in developing motor neurons causes axon guidance defects in several subsets of cranial motor neurons, especially in the hypoglossal nerve (Kobayashi et al., 2011). We next examined the axonal projections of motor neurons in RhoA-Olig2-CKO embryos by crossing them with Hb9-EGFP mice, in which EGFP is expressed by motor neurons (Wichterle et al., 2002). We did not detect any obvious defects in $\mathrm{EGFP}^{+}$axonal projections of motor neurons in RhoA-Olig2-CKO embryos compared with control mice (Fig. $5 A-D$ ). We also examined motor axon projections using whole-mount immunostaining for neurofilaments, but we did not find any obvious differences between control and RhoAOlig2-CKO embryos (data not shown). In addition, dendrites of motor neurons did not appear to project to the other side of the spinal cord in RhoA-Olig2-CKO mice (Fig. 5E,F). These results suggest that RhoA does not grossly affect axonal and dendrite projections of motor neurons in the spinal cord. The discrepancy in results between our findings and the previous study may be attributable to differences in the efficiency to suppress the signaling activity between RhoA deletion and dominant-negative RhoA and/or differences in induction of Cre/loxP recombination between Olig2-Cre and dopamine $\beta$-hydroxylase-Cre drivers.

In the cervical and lumbar levels of the spinal cord, motor neurons are divided into two columns: the medial motor column (MMC), which contains neurons innervating axial muscles, and the lateral motor column (LMC), which contains neurons innervating limb muscles (Jessell, 2000; Dasen and Jessell, 2009). MMC and LMC are further split into two divisions, medial and lateral, based on the dorsal or ventral origins of the target muscle. Each column and division can be identified using specific markers. LMC neurons are defined by Foxp1 expression, MMC and medial LMC neurons by Isl1 expression, and medial MMC neurons by expression of Lhx3 (Tsuchida et al., 1994; Sharma et al., 1998; Dasen et al., 2008; Rousso et al., 2008). To study motor neuron organization in RhoA-Olig2-CKO embryos, we examined the distribution of the motor columns and divisions using these markers. However, we did not find any obvious differences between control and RhoA-Olig2-CKO embryos (Fig. 6; data not shown). We also did not find any defects in the distribution of motor columns in the thoracic spinal cord of RhoA-Olig2-CKO embryos (data not shown). Thus, RhoA is unlikely to play a role in the differentiation and distribution of columns and divisions of motor neurons.

Together, RhoA does not appear to affect the differentiation, migration, or axonal projections of motor neurons but partly contributes to motor neuron survival in the developing spinal cord. This suggests that subtle defects in motor neuron development in RhoA-Olig2-CKO mice are unlikely to cause the observed rabbit-like hopping gait.

\section{RhoA-ChAT-CKO mice do not show a hopping gait}

To further exclude the possibility that defects in the motor neurons in RhoA-Olig2-CKO mice are responsible for the hopping gait behavior, we deleted RhoA in motor neurons using ChATCre mice (Rossi et al., 2011). In ChAT-Cre mice, unlike Olig2Cre mice, Cre recombination does not occur in motor neuron progenitors but occurs in differentiated motor neurons at approximately E12.5 [compare Cre/loxP-recombined cells (i.e., 
A

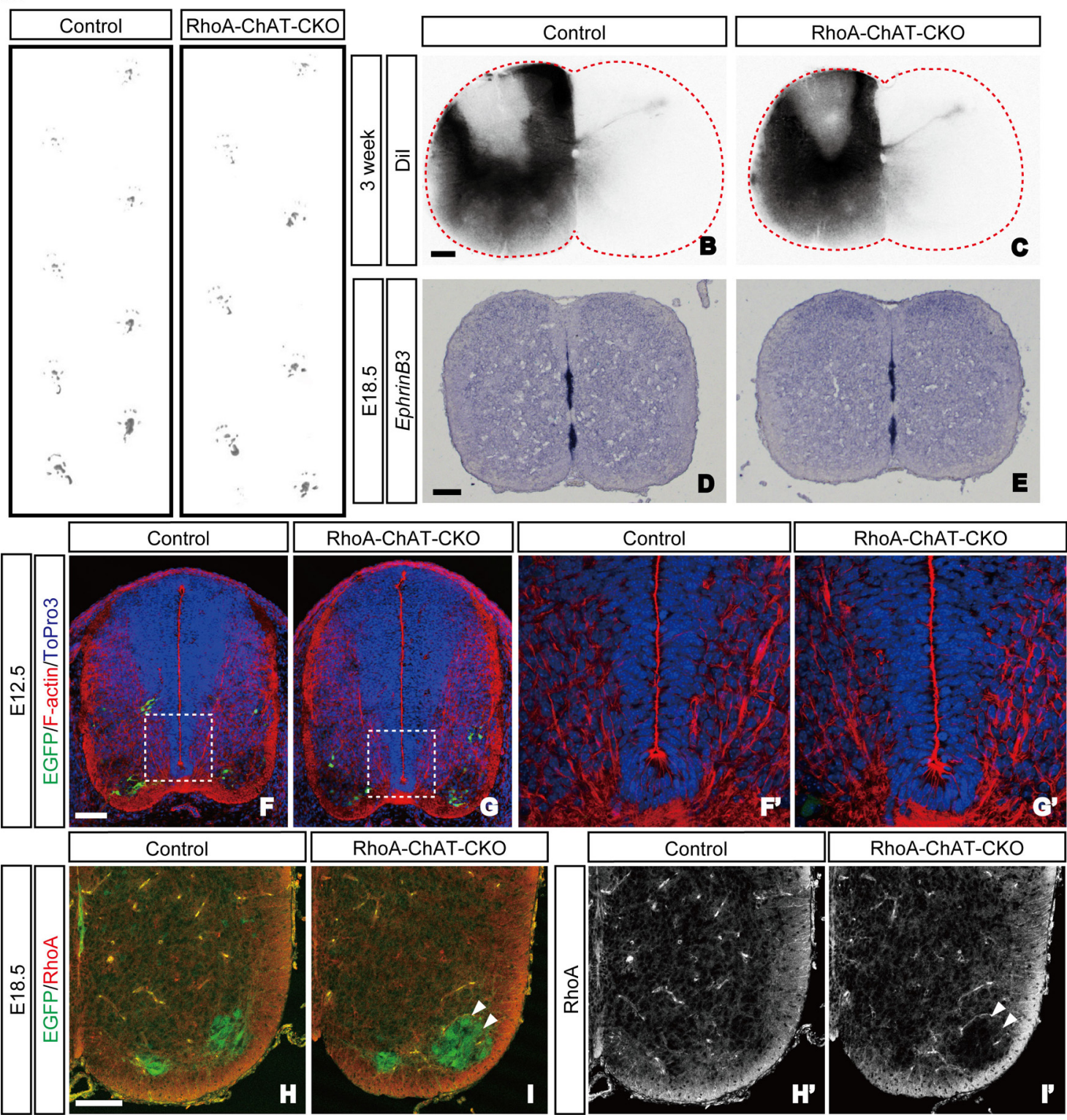

Figure 7. Normal gait, nerve fiber projections across the spinal cord midline, ephrinB3 expression at the midline, and apical organization of the neuroepithelium in RhoA-ChAT-CKO mice. A, Hindlimb footprint patterns of control and RhoA-ChAT-CKO mice. B, C, Tracing of neuronal projections by Dil. There were no overt differences in neuronal projections between control and RhoA-ChAT-CKO mice. D, E, EphrinB3 expression was not altered in RhoA-ChAT-CKO embryos at E18.5. $\boldsymbol{F}, \mathbf{G}, \boldsymbol{F}^{\prime}, \boldsymbol{G}^{\prime}$, Apical F-actin staining in the ventral spinal cord was not disrupted in RhoA-ChAT-CK0 embryos at E12.5. Cre/loxP-recombined cells were visualized by crossing RhoA-ChAT-CKO mice with a stop-floxed EGFP reporter mouse line. $\boldsymbol{H}, \boldsymbol{I}, \boldsymbol{H}^{\prime}, \boldsymbol{I}^{\prime}$, Almost all the motor neurons were (re/loxP recombined (EGFP ${ }^{+}$), and immunopositive signals for RhoA were almost completely abrogated in motor neurons of RhoA-ChAT-CK0 embryos at E18.5 (arrowheads). Scale bars, $100 \mu \mathrm{m}$.

$\mathrm{EGFP}^{+}$cells) in Figs. $2 \mathrm{E}, \mathrm{F}$ and $\left.7 \mathrm{~F}, \mathrm{G}\right]$. Rho $A^{\text {flox/flox }}$; ChAT-Cre (hereafter referred to as RhoA-ChAT-CKO) mice were born in the expected Mendelian ratios. In RhoA-ChAT-CKO mice, the RhoA protein was almost completely abrogated at E18.5 (Fig. $7 \mathrm{H}, \mathrm{I})$. However, these mutants did not show a hopping gait and did not exhibit any obvious defects in nerve fiber projections across the midline either in the formation of an ephrinB3 ${ }^{+}$midline or in apical organization (Fig. 7A-G). These results suggest that the loss of RhoA in apically localized progenitor cells, but not in differentiated motor neurons, is responsible for the aberrant neural circuitry underlying the hopping gait.

\section{RhoA-Wnt1-CKO mice exhibit a hopping gait}

Next, to examine whether appropriate midline structures in the dorsal spinal cord are also necessary for the proper development of locomotor neural circuits, we deleted RhoA using the Wnt1Cre driver in which Cre is expressed by progenitors in the dorsal, but not ventral, spinal cord (Hsu et al., 2010). Although most ( $\sim 80 \%$ ) of the RhoAflox/flox; Wnt1-Cre (hereafter referred to as RhoA-Wnt1-CKO) mice die before birth as a result of exencephaly (Katayama et al., 2011), a small percentage did not develop exencephaly and were born. Interestingly, the surviving mice also displayed a rabbit-like hopping gait (Fig. 8A). Histologically, RhoA-Wnt1-CKO spinal cords exhibited an expansion of the dorsal gray matter (Fig. $8 B, C$ ). We also examined the projections of corticospinal neurons and spinal interneurons in RhoAWnt1-CKO mice using the same methods used for RhoA-Olig2CKO mice. Although the number of CST axons markedly decreased in RhoA-Wnt1-CKO mice, probably as a result of brain malformation (Katayama et al., 2011), some of the CST 


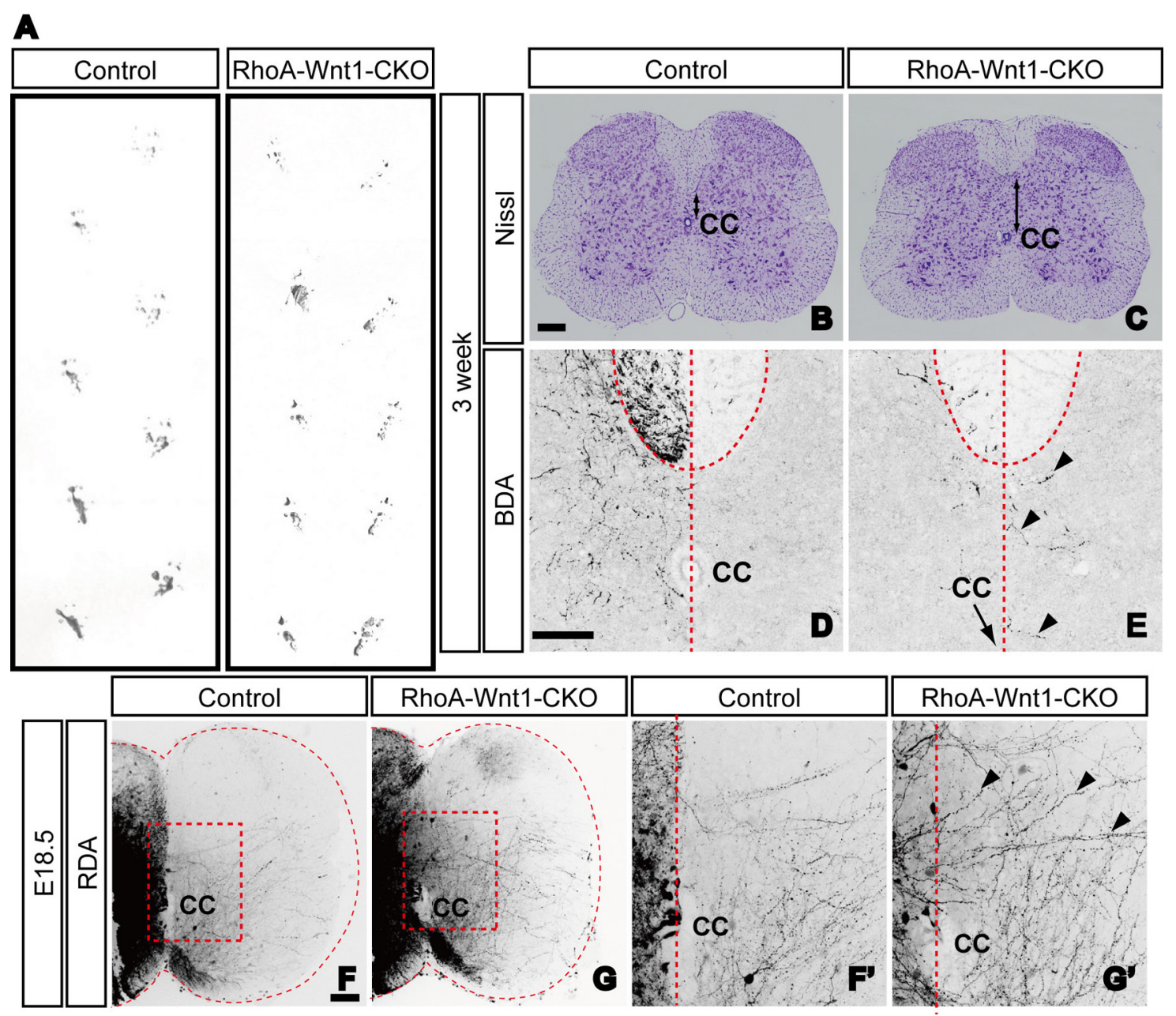

Figure 8. RhoA-Wnt1-CKO mice exhibit a rabbit-like hopping gait and aberrant projections of nerve fibers across the spinal cord midline. $A$, Hindlimb footprint patterns of control and RhoA-Wnt1-CKO mice. $B, C$, Nissl-stained sections of the spinal cords of 3-week-old RhoA-Wnt1-CKO mice showing expansion of the dorsal gray matter. $\boldsymbol{D}, \boldsymbol{E}$, Anterograde tracing of the CST by BDA. Some CST axons aberrantly crossed the midline and projected to the other side of the spinal cord in RhoA-Wnt1-CKO mice (arrowheads). $\boldsymbol{F}, \mathbf{G}, \boldsymbol{F}^{\prime}, \boldsymbol{G}^{\prime}$, Tracing of spinal interneurons by RDA. Numerous interneurons projected to the contralateral side in RhoA-Wnt1-CKO mice (arrowheads). CC, Central canal. Scale bars, $100 \mu \mathrm{m}$.

axons aberrantly crossed the midline through the expanded dorsal gray matter and projected to the other side of the spinal cord (Fig. $8 D, E$ ). Numerous interneurons also projected aberrantly to the contralateral side of the spinal cord through the expanded dorsal gray matter (Fig. $8 F, G$ ). Although we examined the location and number of interneuron subpopulations in RhoAWnt1-CKO embryos using the same markers as analyzed in RhoA-Olig2-CKO embryos, we did not find obvious differences between control and RhoA-Wnt1-CKO embryos at E13.5 (data not shown), indicating that cell fate determination and migration of these spinal interneurons are unaffected in RhoA-Wnt1-CKO embryos.

Disruption of cell-cell adhesions in RhoA-Wnt1-CKO embryos started at approximately E12.5 in the dorsal portion of the spinal cord in which Wnt1-Cre-mediated Cre/loxP recombination was induced (Fig. 9A,B). The dorsal portion of the central canal was disrupted and the dorsal gray matter was expanded at E14.5 (Fig. 9C,D). In addition, ephrinB3 expression at the midline was absent in the dysplastic region (Fig. 9E,F). These results suggest that RhoA is indispensable for the maintenance of neuroepithelial organization not only in the ventral but also in the dorsal portion of the developing spinal cord. This further supports the idea that RhoA-dependent AJs and neuroepithelial or- ganization in the spinal cord are necessary for the formation of proper locomotor circuits.

\section{Discussion}

In this study, we show that conditional deletion of RhoA in the ventral or dorsal spinal cord by Olig2-Cre and Wnt1-Cre drivers, respectively, induces loss of apical AJs in spinal cord progenitors and disorganization of the neuroepithelium. The dysplastic region lacks ephrinB3 expression and nerve fibers of both corticospinal neurons and spinal interneurons aberrantly cross the midline to the other side of the spinal cord likely through the ephrinB3-negative region (Fig. 10). This results in neural circuit defects that alter walking behavior. Our results demonstrate that RhoA-dependent neuroepithelial organization is required for the development of proper midline structures, which are necessary for appropriate left-right locomotor behavior.

\section{RhoA-dependent neuroepithelial organization in the developing spinal cord prevents aberrant neuronal projections across the midline}

AJs are protein complexes that are essential for intercellular adhesion in epithelial tissues. Disruption of AJ formation in the developing nervous system results in severe malformations 


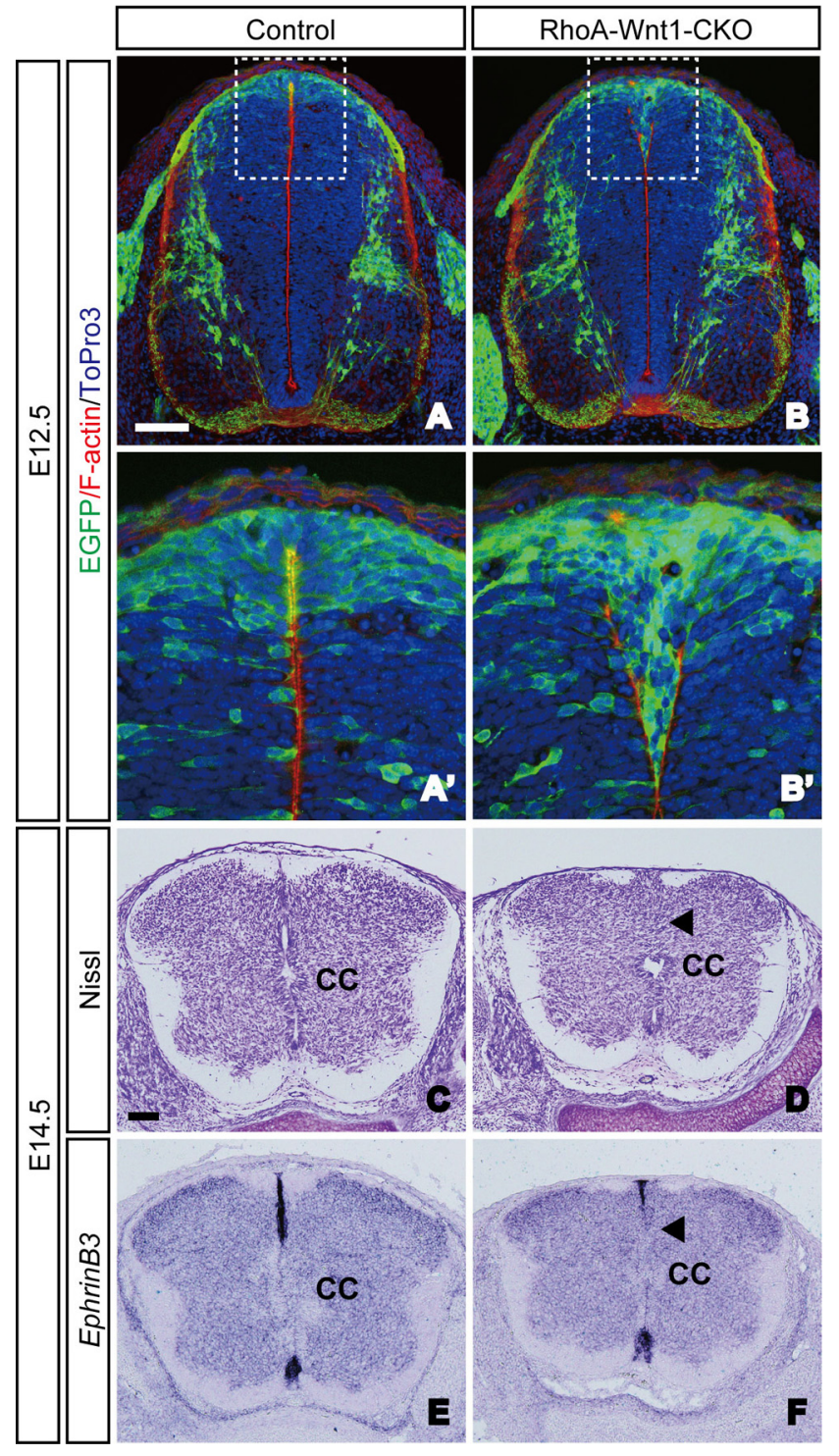

Figure 9. Disorganization of the neuroepithelium and impaired ephrinB3 expression at the midline in the dorsal spinal cords of RhoA-Wnt1-CKO embryos. $\boldsymbol{A}, \boldsymbol{B}, \boldsymbol{A}^{\prime}, \boldsymbol{B}^{\prime}$, Apical F-actin staining in the dorsal spinal cord was disrupted in RhoA-Wnt1-CKO embryos at E12.5. Cre/ loxP-recombined cells were visualized using a stop-floxed EGFP reporter mouse line. $\boldsymbol{C}, \boldsymbol{D}$, In E14.5 RhoA-Wnt1-CK0 embryos, the dorsal portion of the central canal was collapsed (arrowhead), resulting in expansion of the dorsal gray matter. $\boldsymbol{E}, \boldsymbol{F}$, EphrinB3 expression was partly absent in the dorsal gray matter of RhoA-Wnt1-CKO embryos (arrowhead). CC, Central canal. Scale bars, $100 \mu \mathrm{m}$.

(Stepniak et al., 2009). In addition to their major role in maintaining cell-to-cell adhesion, defects in AJs appear to affect proliferation and differentiation of neural progenitor cells (Stepniak et al., 2009). RhoA deletion in the telencephalon, mesencephalon, and spinal cord all cause disruption of AJs in neural progenitor cells and disorganization of the neuroepithelium (Herzog et al., 2011; Katayama et al., 2011; Cappello et al., 2012), demonstrating that RhoA regulates AJ formation and maintains neuroepithelial structures in the developing CNS. However, it remained unknown whether neural circuits in the developing spinal cord are also impacted by defects in AJ formation and changes in neuroepithelial organization, because loss of RhoA throughout the spinal cord causes prenatal death of mutant mice (Herzog et al., 2011). To circumvent this problem, we deleted RhoA in a subset of neural progenitor cells in the developing spinal cord using an
Olig2-Cre driver and created mutant mice that survived until adulthood. We found that RhoA-Olig2-CKO mice exhibited a rabbit-like hopping gait that could be caused by the aberrant left-right neuronal projections in the spinal cord. Indeed, we observed aberrant projections of corticospinal neurons and spinal interneurons across the spinal cord midline in RhoA-Olig2$\mathrm{CKO}$ mice. In these mice, progenitors in the RhoA-deleted area showed defects in the formation of apical AJs, which resulted in disorganization of the neuroepithelium. Consequently, the ventricular zone and lumen of the dysplastic region were lost, creating a direct connection between the left and right sides of the gray matter. Spinal interneurons and corticospinal neurons projected to the other side of the spinal cord through the dysplastic region that lacked ephrinB3 expression. During development, the left and right halves of the spinal cord face each other with apical AJs across a shallow lumen. Disruption of AJs could create a direct connection between the left and right halves of the spinal cord and allow aberrant neuronal projections to cross the midline. Therefore, the results presented here suggest that proper formation of apical AJs and appropriate neuroepithelial organization in the developing spinal cord are important for the development of normal neural circuits.

\section{RhoA-Wnt1-CKO mice exhibit a similar phenotype to RhoA-Olig2-CKO mice}

Intriguingly, defects not only in the ventral region of the midline but also in the dorsal region caused a similar locomotor phenotype. Although mutant mice with dysfunctional ephrinB3/EphA4 signaling exhibit aberrant neuronal projections both dorsal and ventral to the central canal (Kullander et al., 2003; Beg et al., 2007; Fawcett et al., 2007; Iwasato et al., 2007; Wegmeyer et al., 2007), the ventral commissure alone is responsible for inducing synchronous firing of bilateral motor neurons in EphA4-deficient mice (Restrepo et al., 2011). In RhoA-Olig2-CKO mice, the dysplastic region was located in the ventral part of the spinal cord and aberrant commissural projections were mainly localized in the ventral portion of the gray matter. In contrast, the dysplastic region in RhoA-Wnt1-CKO mice was located in the dorsal portion of the spinal cord and aberrant commissural projections were mainly observed dorsal to the central canal, although both mutant lines exhibited a rabbit-like hopping gait. RhoA-Wnt1CKO mice had an expanded dorsal gray matter, and the central canal was localized more ventrally than control mice. Thus, the aberrantly projecting fibers that cross ventrally in the absence of ephrinB3/EphA4 signaling may correspond to fibers that cross dorsal to the central canal in RhoA-Wnt1-CKO mice.

RhoA is also suggested to be a possible downstream molecule of EphA4 signaling to repel growth cones (Iwasato et al., 2007). Therefore, RhoA-deficient nerve fibers of corticospinal neurons and spinal interneurons might not be repelled at the midline by ephrinB3, a ligand for EphA4. However, because Olig2 and Wnt1 are not expressed by corticospinal neurons in the cortex (Ono et al., 2008; Hsu et al., 2010), aberrant axonal crossing of the CSTs is unlikely to be caused by the cell-autonomous loss of function of RhoA. In contrast, as Olig2 ${ }^{+}$progenitors differentiate into a subset of interneurons (Chen et al., 2011), we cannot exclude the possibility of defects in axon guidance of interneurons in addition to the midline defects.

\section{Loss of ephrinB3 expression in the dysplastic area}

How does loss of RhoA affect ephrinB3 expression at the midline? Although the identity of the ephrinB3 ${ }^{+}$cells and the mechanisms of midline establishment in the spinal cord remain unclear, it has 
been shown that, during development, the expression of ephrinB3 starts in the floor and roof plates and gradually expands medially to form the midline with a gradual closure of the ventricular zone and lumen (Imondi et al., 2000). In our study, the ventricular zone and lumen were partly lost before the establishment of the ephirinB3 ${ }^{+}$midline in RhoAOlig2-CKO and RhoA-Wnt1-CKO embryos, and expansion of ephrinB3 expression appeared to be prevented at the dysplastic region. These results indicate that proper neuroepithelial organization maintained by RhoA is important for the establishment of an ephrinB3 $3^{+}$midline. The identity of the cells expressing ephrinB3 and the precise mechanisms of midline formation will be elucidated in future research.

In conclusion, the results presented here demonstrate that RhoA prevents aberrant neuronal projections across the midline by maintaining apical AJs and the organization of the neuroepithelium in the developing spinal cord and is indispensable for the proper formation of the neural circuitry controlling walking behavior. These findings give additional breadth to the variety of physiological functions of RhoA in the developing mammalian nervous system.

\section{References}

Beg AA, Sommer JE, Martin JH, Scheiffele P (2007) alpha2-Chimaerin is an essential EphA4 effector in the assembly of neuronal locomotor circuits. Neuron 55:768-778.

Canty AJ, Murphy M (2008) Molecular mechanisms of axon guidance in the developing corticospinal tract. Prog Neurobiol 85:214-235.

Cappello S, Böhringer CR, Bergami M, Conzelmann KK, Ghanem A, Tomassy GS, Arlotta P, Mainardi M, Allegra M, Caleo M, van Hengel J, Brakebusch C, Götz M (2012) A radial glia-specific role of RhoA in double cortex formation. Neuron 73:911-924.

Caspary T, Anderson KV (2003) Patterning cell types in the dorsal spinal cord: what the mouse mutants say. Nat Rev Neurosci 4:289-297.

Chauhan BK, Lou M, Zheng Y, Lang RA (2011) Balanced Racl and RhoA activities regulate cell shape and drive invagination morphogenesis in epithelia. Proc Natl Acad Sci U S A 108:18289-18294.

Chen JA, Huang YP, Mazzoni EO, Tan GC, Zavadil J, Wichterle H (2011) Mir-17-3p controls spinal neural progenitor patterning by regulating Olig2/Irx3 cross-repressive loop. Neuron 69:721-735.

Danielian PS, Muccino D, Rowitch DH, Michael SK, McMahon AP (1998) Modification of gene activity in mouse embryos in utero by a tamoxifeninducible form of Cre recombinase. Curr Biol 8:1323-1326.

Dasen JS, Jessell TM (2009) Hox networks and the origins of motor neuron diversity. Curr Top Dev Biol 88:169-200.

Dasen JS, De Camilli A, Wang B, Tucker PW, Jessell TM (2008) Hox repertoires for motor neuron diversity and connectivity gated by a single accessory factor, FoxP1. Cell 134:304-316.

Dessaud E, Yang LL, Hill K, Cox B, Ulloa F, Ribeiro A, Mynett A, Novitch BG, Briscoe J (2007) Interpretation of the sonic hedgehog morphogen gradient by a temporal adaptation mechanism. Nature 450:717-720.

Dottori M, Hartley L, Galea M, Paxinos G, Polizzotto M, Kilpatrick T, Bartlett PF, Murphy M, Köntgen F, Boyd AW (1998) EphA4 (Sek1) receptor tyrosine kinase is required for the development of the corticospinal tract. Proc Natl Acad Sci U S A 95:13248-13253.

Fawcett JP, Georgiou J, Ruston J, Bladt F, Sherman A, Warner N, Saab BJ, Scott R, Roder JC, Pawson T (2007) Nck adaptor proteins control the organization of neuronal circuits important for walking. Proc Natl Acad Sci U S A 104:20973-20978.

Fedtsova NG, Turner EE (1995) Brn-3.0 expression identifies early postmitotic CNS neurons and sensory neural precursors. Mech Dev 53:291-304.
Gianino S, Stein SA, Li H, Lu X, Biesiada E, Ulas J, Xu XM (1999) Postnatal growth of corticospinal axons in the spinal cord of developing mice. Brain Res Dev Brain Res 112:189-204.

Goulding M (2009) Circuits controlling vertebrate locomotion: moving in a new direction. Nat Rev Neurosci 10:507-518.

Herzog D, Loetscher P, van Hengel J, Knüsel S, Brakebusch C, Taylor V, Suter U, Relvas JB (2011) The small GTPase RhoA is required to maintain spinal cord neuroepithelium organization and the neural stem cell pool. J Neurosci 31:5120-5130.

Hsu W, Mirando AJ, Yu HM (2010) Manipulating gene activity in Wnt1expressing precursors of neural epithelial and neural crest cells. Dev Dyn 239:338-345.

Imondi R, Wideman C, Kaprielian Z (2000) Complementary expression of transmembrane ephrins and their receptors in the mouse spinal cord: a possible role in constraining the orientation of longitudinally projecting axons. Development 127:1397-1410.

Iwasato T, Katoh H, Nishimaru H, Ishikawa Y, Inoue H, Saito YM, Ando R, Iwama M, Takahashi R, Negishi M, Itohara S (2007) Rac-GAP alphachimerin regulates motor-circuit formation as a key mediator of EphrinB3/EphA4 forward signaling. Cell 130:742-753.

Jessell TM (2000) Neuronal specification in the spinal cord: inductive signals and transcriptional codes. Nat Rev Genet 1:20-29.

Katayama K, Melendez J, Baumann JM, Leslie JR, Chauhan BK, Nemkul N, Lang RA, Kuan CY, Zheng Y, Yoshida Y (2011) Loss of RhoA in neural progenitor cells causes the disruption of adherens junctions and hyperproliferation. Proc Natl Acad Sci U S A 108:7607-7612.

Kiehn O, Kullander K (2004) Central pattern generators deciphered by molecular genetics. Neuron 41:317-321.

Kobayashi K, Takahashi M, Matsushita N, Miyazaki J, Koike M, Yaginuma H, Osumi N, Kaibuchi K, Kobayashi K (2004) Survival of developing motor neurons mediated by Rho GTPase signaling pathway through Rhokinase. J Neurosci 24:3480-3488.

Kobayashi K, Masuda T, Takahashi M, Miyazaki J, Nakagawa M, Uchigashima M, Watanabe M, Yaginuma H, Osumi N, Kaibuchi K (2011) Rho/Rho-kinase signaling pathway controls axon patterning of a specified subset of cranial motor neurons. Eur J Neurosci 33:612-621.

Koh CG (2006) Rho GTPases and their regulators in neuronal functions and development. Neurosignals 15:228-237.

Kullander K, Croll SD, Zimmer M, Pan L, McClain J, Hughes V, Zabski S, DeChiara TM, Klein R, Yancopoulos GD, Gale NW (2001) Ephrin-B3 is the midline barrier that prevents corticospinal tract axons from recrossing, allowing for unilateral motor control. Genes Dev 15:877-888.

Kullander K, Butt SJ, Lebret JM, Lundfald L, Restrepo CE, Rydström A, Klein R, Kiehn O (2003) Role of EphA4 and EphrinB3 in local neuronal circuits that control walking. Science 299:1889-1892.

Lee SK, Pfaff SL (2001) Transcriptional networks regulating neuronal identity in the developing spinal cord. Nat Neurosci 4 [Suppl]:1183-1191.

Lemon RN (2008) Descending pathways in motor control. Annu Rev Neurosci 31:195-218.

Leslie JR, Imai F, Fukuhara K, Takegahara N, Rizvi TA, Friedel RH, Wang F, Kumanogoh A, Yoshida Y (2011) Ectopic myelinating oligodendrocytes in the dorsal spinal cord as a consequence of altered semaphorin $6 \mathrm{D}$ signaling inhibit synapse formation. Development 138:4085-4095. 
Linseman DA, Loucks FA (2008) Diverse roles of Rho family GTPases in neuronal development, survival, and death. Front Biosci 13:657-676.

Melendez J, Stengel K, Zhou X, Chauhan BK, Debidda M, Andreassen P, Lang RA, Zheng Y (2011) RhoA GTPase is dispensable for actomyosin regulation but is essential for mitosis in primary mouse embryonic fibroblasts. J Biol Chem 286:15132-15137.

Nakamura T, Colbert MC, Robbins J (2006) Neural crest cells retain multipotential characteristics in the developing valves and label the cardiac conduction system. Circ Res 98:1547-1554.

Omoto S, Ueno M, Mochio S, Yamashita T (2011) Corticospinal tract fibers cross the ephrin-B3-negative part of the midline of the spinal cord after brain injury. Neurosci Res 69:187-195.

Ono K, Takebayashi H, Ikeda K, Furusho M, Nishizawa T, Watanabe K, Ikenaka K (2008) Regional- and temporal-dependent changes in the differentiation of Olig2 progenitors in the forebrain, and the impact on astrocyte development in the dorsal pallium. Dev Biol 320:456-468.

Restrepo CE, Margaryan G, Borgius L, Lundfald L, Sargsyan D, Kiehn O (2011) Change in the balance of excitatory and inhibitory midline fiber crossing as an explanation for the hopping phenotype in EphA4 knockout mice. Eur J Neurosci 34:1102-1112.

Rossi J, Balthasar N, Olson D, Scott M, Berglund E, Lee CE, Choi MJ, Lauzon D, Lowell BB, Elmquist JK (2011) Melanocortin-4 receptors expressed by cholinergic neurons regulate energy balance and glucose homeostasis. Cell Metab 13:195-204.

Rousso DL, Gaber ZB, Wellik D, Morrisey EE, Novitch BG (2008) Coordi- nated actions of the forkhead protein Foxp1 and Hox proteins in the columnar organization of spinal motor neurons. Neuron 59:226-240.

Sharma K, Sheng HZ, Lettieri K, Li H, Karavanov A, Potter S, Westphal H, Pfaff SL (1998) LIM homeodomain factors Lhx3 and Lhx4 assign subtype identities for motor neurons. Cell 95:817-828.

Stepniak E, Radice GL, Vasioukhin V (2009) Adhesive and signaling functions of cadherins and catenins in vertebrate development. Cold Spring Harb Perspect Biol 1:a002949.

Sürmeli G, Akay T, Ippolito GC, Tucker PW, Jessell TM (2011) Patterns of spinal sensory-motor connectivity prescribed by a dorsoventral positional template. Cell 147:653-665.

Tsuchida T, Ensini M, Morton SB, Baldassare M, Edlund T, Jessell TM, Pfaff SL (1994) Topographic organization of embryonic motor neurons defined by expression of LIM homeobox genes. Cell 79:957-970.

Wegmeyer H, Egea J, Rabe N, Gezelius H, Filosa A, Enjin A, Varoqueaux F, Deininger K, Schnütgen F, Brose N, Klein R, Kullander K, Betz A (2007) EphA4-dependent axon guidance is mediated by the RacGAP alpha2chimaerin. Neuron 55:756-767.

Wichterle H, Lieberam I, Porter JA, Jessell TM (2002) Directed differentiation of embryonic stem cells into motor neurons. Cell 110:385-397.

Yokoyama N, Romero MI, Cowan CA, Galvan P, Helmbacher F, Charnay P, Parada LF, Henkemeyer M (2001) Forward signaling mediated by ephrin-B3 prevents contralateral corticospinal axons from recrossing the spinal cord midline. Neuron 29:85-97. 